\title{
Do physicians correctly calculate thromboembolic risk scores? A comparison of concordance between manual and computer-based calculation of $\mathrm{CHADS}_{2}$ and $\mathrm{CHA}_{2} \mathrm{DS}_{2}-\mathrm{VASc}$ scores
}

\author{
M. A. Esteve-Pastor, ${ }^{1}$ F. Marín, ${ }^{1}$ V. Bertomeu-Martinez, ${ }^{2}$ I. Roldán-Rabadán, ${ }^{3}$ Á. \\ Cequier-Fillat, ${ }^{4}$ L. Badimon, ${ }^{5}$ J. Muñiz-García, ${ }^{6}$ M. Valdés, ${ }^{1}$ M. Anguita-Sánchez, ${ }^{7}$ and \\ FANTASIIA Study Investigators \\ ${ }^{I}$ Department of Cardiology, Hospital Clínico Universitario Virgen de la Arrixaca, Murcia, ${ }^{2}$ Department of \\ Cardiology, Hospital Universitario San Juan, Alicante, ${ }^{3}$ Department of Cardiology, Hospital La Paz, Madrid, ${ }^{4}$ \\ Department of Cardiology, Hospital de Bellvitge,${ }^{5}$ Cardiovascular Research Center, CSIC-ICCC, Hospital de la \\ Santa Creu i Sant Pau, IIB-Sant Pau, Barcelona, ${ }^{6}$ Department of Cardiology, Hospital Universitario A Coruña, La \\ Coruña and ${ }^{7}$ Department of Cardiology, Hospital Universitario Reina Sofía, Córdoba, Spain
}

\begin{abstract}
Background. Clinical risk scores, $\mathrm{CHADS}_{2}$ and $\mathrm{CHA}_{2} \mathrm{DS}_{2}$-VASc scores, are the established tools for assessing stroke risk in patients with atrial fibrillation $(\mathrm{AF})$.

Aim. The aim of this study is to assess concordance between manual and computer-based calculation of CHADS 2 and $\mathrm{CHA}_{2} \mathrm{DS}_{2}$-VASc scores, as well as to analyse the patient categories using $\mathrm{CHADS}_{2}$ and the potential improvement on stroke risk stratification with $\mathrm{CHA}_{2} \mathrm{DS}_{2}$-VASc score.

Methods. We linked data from Atrial Fibrillation Spanish registry FANTASIIA. Between June 2013 and March 2014, 1318 consecutive outpatients were recruited. We explore the concordance between manual scoring and computerbased calculation. We compare the distribution of embolic risk of patients using both $\mathrm{CHADS}_{2}$ and $\mathrm{CHA}_{2} \mathrm{DS}_{2}-\mathrm{VASc}$ scores

Results. The mean age was $73.8 \pm 9.4$ years, and $758(57.5 \%)$ were male. For $\mathrm{CHADS}_{2}$ score, concordance between manual scoring and computer-based calculation was $92.5 \%$, whereas for $\mathrm{CHA}_{2} \mathrm{DS}_{2}$-VASc score was $96.4 \%$. In $\mathrm{CHADS}_{2}$ score, $6.37 \%$ of patients with AF changed indication on antithrombotic therapy $(3.49 \%$ of patients with no treatment changed to need antithrombotic treatment and $2.88 \%$ of patients otherwise). Using $\mathrm{CHA}_{2} \mathrm{DS}_{2}$-VASc score, only $0.45 \%$ of patients with AF needed to change in the recommendation of antithrombotic therapy.

Conclusion. We have found a strong concordance between manual and computer-based score calculation of both $\mathrm{CHADS}_{2}$ and $\mathrm{CHA}_{2} \mathrm{DS}_{2}$-VASc risk scores with minimal changes in anticoagulation recommendations. The use of $\mathrm{CHA}_{2} \mathrm{DS}_{2}$-VASc score significantly improves classification of AF patients at low and intermediate risk of stroke into higher grade of thromboembolic score. Moreover, $\mathrm{CHA}_{2} \mathrm{DS}_{2}$-VASc score could identify 'truly low risk' patients compared with $\mathrm{CHADS}_{2}$ score.
\end{abstract}

\section{Key words}

Atrial fibrillation, stroke risk score, oral anticoagulation, antithrombotic treatment, $\mathrm{CHA}_{2} \mathrm{DS}_{2}-\mathrm{VASc}$ score 


\section{Introduction}

Atrial fibrillation (AF) is the most common cardiac rhythm disorder in general population which is associated with high risk of mortality and morbidity from stroke events. ${ }^{1}$ Patients who survive a non-fatal stroke are more likely to suffer recurrences. ${ }^{2}$ Stroke risk in AF is not homogeneous and is closely correlated with bleeding risk. ${ }^{3,4}$ In this context, risk stratification schemes try to help in clinical decision making. ${ }^{5}$

The $\mathrm{CHADS}_{2}$ score (Table 1) was developed to identify AF patients with high risk for stroke. ${ }^{5}$ Despite stroke risk in AF being a continuum, the most risk stratification schemes have been used to 'artificially' categorise patients into low risk $\left(\mathrm{CHADS}_{2}=0\right)$, moderate risk $\left(\mathrm{CHADS}_{2}=1\right)$ and high risk $\left(\mathrm{CHADS}_{2} \geq\right.$ 2) stroke strata. ${ }^{2,} 6$ The $\mathrm{CHADS}_{2}$ schema is widely used due to its simplicity and ease, but different analysis showed that the classical $\mathrm{CHADS}_{2}$ score generates a large intermediate risk group (>60\%), and a $\mathrm{CHADS}_{2}=0$ does not reliably identify AF patients who are at low risk. ${ }^{1,6}$ In 2009 new Birmingham schema - $\mathrm{CHA}_{2} \mathrm{DS}_{2}-\mathrm{VASc}$ (Table 1) was proposed, being more inclusive of common stroke risk factors in $\mathrm{AF}$. $\mathrm{CHA}_{2} \mathrm{DS}_{2}$-VASc significantly improves the predictive value of the $\mathrm{CHADS}_{2}$, and this score has been used as the basis of treatment recommendations. ${ }^{1,6} \mathrm{CHA}_{2} \mathrm{DS}_{2}$-VASc score consistently performs better accuracy in the identification of truly low-risk patients $\left(\mathrm{CHA}_{2} \mathrm{DS}_{2}-\mathrm{VASc}=0\right)$ with $\mathrm{AF}$ who do not need any antithrombotic therapy ${ }^{3,7}$; and this score performs at least as good as CHADS $_{2}$ in identifying high-risk patients $\left(\mathrm{CHA}_{2} \mathrm{DS}_{2}-\mathrm{VASc} \geq 2\right)$ who need antithrombotic therapy (Class I recommendation) ${ }^{.8}$ Also the $\mathrm{CHA}_{2} \mathrm{DS}_{2}-\mathrm{VASc}$ score classifies only a small proportion $(<15.0 \%)$ as moderate risk $\left(\mathrm{CHA}_{2} \mathrm{DS}_{2}-\right.$ VASc $=1$ ) when oral anticoagulation should be considered (Class IIa recommendation). ${ }^{1,7,9}{ }^{C H A_{2} D_{2}-}$ VASc scheme successfully predicts cardiovascular events and mortality, but not major bleeds. ${ }^{10}$ Indeed, HAS-BLED score is better for predicting major bleeding than $\mathrm{CHADS}_{2}$ or $\mathrm{CHA}_{2} \mathrm{DS}_{2}-\mathrm{VASc}$. So it is important the knowledge and use of both thrombotic and bleeding risk schemes. ${ }^{4}$

Table 1. Assessment of risk score with $\mathrm{CHADS}_{2}$ and $\mathrm{CHA}_{2} \mathrm{DS}_{2}-\mathrm{VASc}$ score ${ }^{1,17}$

\begin{tabular}{lccc}
\hline $\mathrm{CHADS}_{2}$ & Score & $\mathrm{CHA}_{2} \mathrm{DS}_{2}$-VASc & Score \\
\hline Congestive heart failure & 1 & Congestive heart failure & 1 \\
Hypertension & 1 & Hypertension & 1 \\
Age $\geq 75$ years & 1 & Age $\geq 75$ years & 2 \\
Diabetes mellitus & 1 & Diabetes mellitus & 1 \\
Stroke/TIA & 2 & Stroke/TIA & 2 \\
& & Vascular disease & 1 \\
& & Aged 65-74 years & 1 \\
& & Sex category (female) & 1 \\
Maximum score & 6 & Maximum score & 9
\end{tabular}

Despite the evidence in favour of antithrombotic therapy for stroke prevention, there are still many patients with AF underdiagnosed or undertreated. ${ }^{11}$ Euro Heart Survey in $\mathrm{AF}^{12}$ provided a detailed description of antithrombotic drugs related to stroke risk stratification schemes in real life cardiology practice. This survey showed how antithrombotic therapy prescription was quite high throughout all risk categories, irrespective of the stroke risk stratification scheme used. This suboptimal use may, among several reasons, be related to unawareness among clinicians to guidelines and risk stratification schemes. In the last focused update of the European Society of Cardiology guidelines for the management of AF strongly recommend a practice shift towards greater focus on the identification of patients without thromboembolic risk factors who do not benefit from antithrombotic therapy instead to trying to focus on 
identifying high-risk patients. ${ }^{13,}{ }^{14}$ At present, $\mathrm{CHA}_{2} \mathrm{DS}_{2}$-VASc risk score has largely been validated in several cohorts of patients with $\mathrm{AF}$ around the world to correctly reclassified thromboembolic risk in patients with intermediate risk with $\mathrm{CHADS}_{2}$ because despite the modest degree of the risk discrimination improvement, the clinical consequence of reclassification could be substantial. ${ }^{15,16}$

The aim of this study was to analyse the quality and applicability assessment of stroke risk scores in clinical practice and its influence on antithrombotic therapy in a wide cohort through FANTASIIA (Fibrilación Auricular: influencia del Nivel y Tipo de Anticoagulación Sobre la incidencia de Ictus y Accidentes hemorrágicos) national registry. Our objective was to assess concordance between manual and computer-based calculation of $\mathrm{CHADS}_{2}$ and $\mathrm{CHA}_{2} \mathrm{DS}_{2}$-VASc scores. In addition, this study aims to analyse that patients categorised as low and intermediate risk of stroke using $\mathrm{CHADS}_{2}$ should improve stroke risk stratification with $\mathrm{CHA}_{2} \mathrm{DS}_{2}$-VASc score.

\section{Methods}

\section{Registry data sources}

For this study, we linked data from Atrial Fibrillation Spanish registry FANTASIIA. FANTASIIA registry holds information on current situation of AF non-valvular in Spanish population. This study assesses incidence of thrombotic and bleeding events at 3 years follow up in non-valvular AF, type of antithrombotic drugs (vitamin $\mathrm{K}$ antagonists (VKA) or new oral anticoagulants) and appropriate recommendation of antithrombotic therapy. Patients with rheumatic mitral valve disease or patients with prosthetic heart valves were excluded.

\section{Study population}

We recruited 1318 consecutive outpatients diagnosed as non-valvular AF from June 2013 to March 2014. This prospective national multicenter observational study included all consecutive patients older than 18 years with non-valvular AF who were treated with oral anticoagulation (VKA or new oral anticoagulants) at least 6 months before a patient's enrolment. Patient management was according to usual local practice without further intervention. The CHADS 2 and $\mathrm{CHA}_{2} \mathrm{DS}_{2}$-VASc scores were calculated for each patient with the relevant variables collected at baseline. These scores were calculated both manually and automatically with computer application.

The FANTASIIA registry complied with the Declaration of Helsinki and the study protocols were approved by San Juan Hospital institutional ethics boards and the Ethic Committee of every participant centre. All participants provided written informed consent.

\section{Statistical analysis}

Continuous variables were tested for normality by the Kolmogorov-Smirnov test. Continuous variables are presented as a mean $\pm \mathrm{SD}$ or median (interquartile range, as appropriate, and categorical variables as a percentage). Kolmogorov-Smirnov test was used to check for normal distribution of continuous data. Unpaired $t$-test or chi-square test was used to compare differences between the two groups. A $P$ value $<0.05$ was accepted as statistically significant. Statistical analyses were performed using spss version (Chicago, IL, USA). 


\section{Results}

Baseline clinical characteristics of the patients are shown in Table 2. A total of 1318 patients were included by 85 Spanish investigators $(80.9 \%$ cardiologists, $10.9 \%$ primary care physicians and $8.3 \%$ internal medicine specialists). The mean age was $73.8 \pm 9.4$ years, and $758(57.5 \%)$ were male. Hypertension was the most prevalent stroke risk factor $(81.0 \%)$ followed by hypercholesterolaemia $(54.0 \%)$ and diabetes $(29.0 \%)$. Other remarkable comorbidities were ischaemic stroke (15.9\%) and major bleeding (3.3\%). At the time of the initial visit, the majority of patients $(77.1 \%)$ were treated with VKA: 927 (71.9\%) with acenocoumarol (the most widely oral anticoagulant used in Spain) and 67 patients $(5.2 \%)$ with warfarin. New oral anticoagulants were used in $22.9 \%$ of patients with AF.

Table 2. Baseline clinical characteristics of studied population $^{\dagger}$

\begin{tabular}{|c|c|}
\hline Patients & $n=1318$ \\
\hline Female sex & $560(42.5)$ \\
\hline Age, years & $73.8 \pm 9.4$ \\
\hline Age $\geq 75$ years & $689(52.3)$ \\
\hline Cardiovascular risk factors & no. $(\%)$ \\
\hline Hypertension & $1068(81.0)$ \\
\hline Hypercholesterolaemia & $711(54.0)$ \\
\hline Diabetes mellitus & $386(29.3)$ \\
\hline Current smoker & $60(4.6)$ \\
\hline Concomitant disease & no. $(\%)$ \\
\hline Renal impairment & $251(19.0)$ \\
\hline Hepatic impairment & $13(1.0)$ \\
\hline Vascular disease & $92(7.0)$ \\
\hline Previous stroke & $210(15.9)$ \\
\hline Thyroid diseases & $173(13.1)$ \\
\hline Current alcoholic/drugs consumption & $210(15.9)$ \\
\hline Major bleeding events & $44(3.3)$ \\
\hline Previous heart disease & $629(47.7)$ \\
\hline Heart failure & $376(28.5)$ \\
\hline Coronary heart disease & $245(18.6)$ \\
\hline $\mathrm{CHADS}_{2}$ score & no. $(\%)$ \\
\hline $\mathrm{CHADS}_{2}=0$ & $64(4.9)$ \\
\hline $\mathrm{CHADS}_{2}=1$ & $318(24.1)$ \\
\hline $\mathrm{CHAD}_{\mathrm{S}} \geq 2$ & $936(71.0)$ \\
\hline $\mathrm{CHA}_{2} \mathrm{DS}_{2}$-VASc score & no. $(\%)$ \\
\hline $\mathrm{CHA}_{2} \mathrm{DS}_{2}-\mathrm{VASc}=0$ & $16(1.2)$ \\
\hline $\mathrm{CHA}_{2} \mathrm{DS}_{2}-\mathrm{VASc}=1$ & $86(6.5)$ \\
\hline $\mathrm{CHA}_{2} \mathrm{DS}_{2}-\mathrm{VASc} \geq 2$ & $1216(92.3)$ \\
\hline HAS-BLED score & no. $(\%)$ \\
\hline HAS-BLED $\geq 3$ & $363(27.7)$ \\
\hline Concomitant treatment ${ }^{\ddagger}$ & no. $(\%)$ \\
\hline Diuretics & $766(59.4)$ \\
\hline $\begin{array}{l}\text { ACE (angiotensin-converting enzyme) } \\
\text { inhibitors }\end{array}$ & $402(31.2)$ \\
\hline Angiotensin receptor blockers & $529(41.0)$ \\
\hline Statins & $726(56.3)$ \\
\hline
\end{tabular}

Table 2. Baseline clinical characteristics of studied population $^{\dagger}$

\begin{tabular}{lc}
\hline Patients & $n=1318$ \\
\hline Antiplatelet therapy & $128(9.9)$ \\
Antithrombotic treatments ${ }^{\ddagger}$ & no. $(\%)$ \\
Vitamin K antagonists & $994(77.1)$ \\
Acenocoumarol & $927(71.9)$ \\
Warfarin & $67(5.2)$ \\
New oral anticoagulants & $296(22.9)$ \\
\end{tabular}

$\uparrow$ Data are presented as observed number (no. (\%)) or mean \pm standard deviation (SD).

I Available for 1290 patients.

CHADS, congestive heart failure, hypertension, age $\geq 75$ years, diabetes mellitus, stroke; HAS-BLED, hypertension, abnormal renal/liver function, stroke, bleeding history or predisposition, labile international normalised ratio, elderly, drugs/alcohol concomitantly; VASc, vascular disease, aged 65-74 years, sex category. 
The $\mathrm{CHADS}_{2}$ score classified $4.9 \%$ as low risk (score $=0$ ), $24.1 \%$ classified as intermediate risk (score $=1$ ) and $71.0 \%$ classified as high risk (score $\geq 2$ ). The $\mathrm{CHA}_{2} \mathrm{DS}_{2}-\mathrm{VASc}$ score classified $1.2 \%$ as low risk (score $=0), 6.5 \%$ classified as intermediate risk $($ score $=1)$ and $92.3 \%$ classified as high risk (score $\geq 2$ ). In this registry, $27.7 \%$ of patients showed high bleeding risk, assessed by HAS-BLED score (score $\geq 3$ ) (Fig. 1).

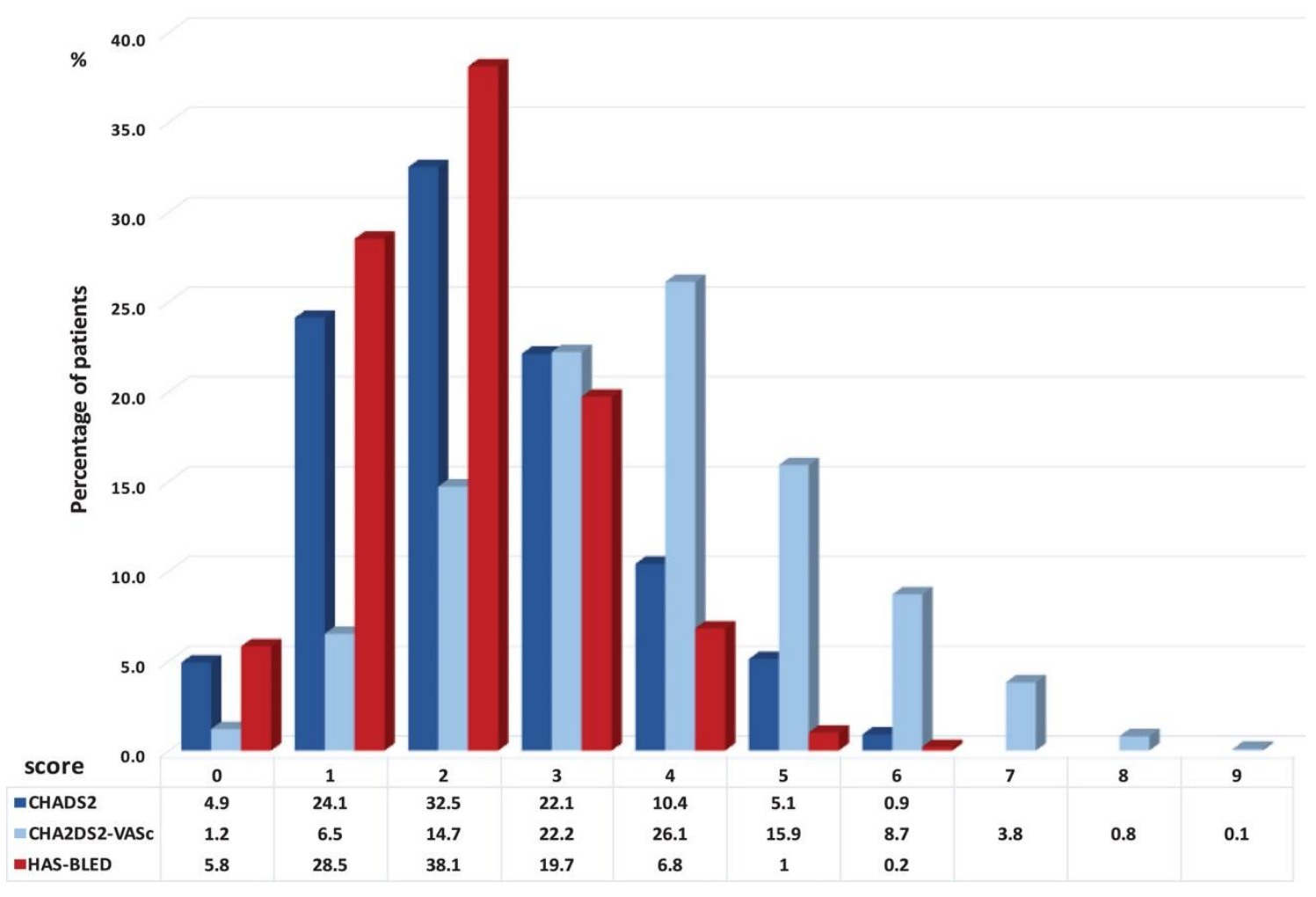

Figure 1. Distribution of stroke risk categories according to $\mathrm{CHADS}_{2}(\square), \mathrm{CHA}_{2} \mathrm{DS}_{2}$-VASc $(\square)$ and HAS-BLED $(\square)$ scores in all study patients. The number (\%) is shown in each bar.

\section{Concordance between manual and computer-based calculation of risk scores}

For $\mathrm{CHADS}_{2}$ score, overall concordance between manual scoring and computer-based calculation was 92.5\%; whereas for $\mathrm{CHA}_{2} \mathrm{DS}_{2}$-VASc score, the concordance between manual and computer-based scoring was $96.4 \%$ (Table 3). We found a strong concordance between the manual and the computerbased score calculation. These results lead to a change in recommendation of oral anticoagulation. In $\mathrm{CHADS}_{2}$ score, $6.37 \%$ of patients with AF changed indication on antithrombotic therapy $(3.49 \%$ of patients with no treatment changed to need antithrombotic treatment and $2.88 \%$ of patients otherwise). Using $\mathrm{CHA}_{2} \mathrm{DS}_{2}$-VASc score, only $0.45 \%$ of patients with $\mathrm{AF}$ needed to change in the recommendation of antithrombotic therapy. 
Table 3. Concordance between manual and computer-based calculation of risk scores

\begin{tabular}{|c|c|c|c|c|c|c|c|c|c|}
\hline & \multicolumn{5}{|c|}{$\mathrm{CHADS}_{2}$ manual } & \multicolumn{4}{|c|}{$\mathrm{CHA}_{2} \mathrm{DS}_{2}-\mathrm{VASc}$ manual } \\
\hline \multirow[t]{4}{*}{$\mathrm{CHADS}_{2}$ app. } & & 0 & 1 & $\geq 2$ & $\mathrm{CHA}_{2}$-VASc app. & & 0 & 1 & $\geq 2$ \\
\hline & 0 & 50 & 5 & 0 & & 0 & 10 & 2 & 0 \\
\hline & 1 & 10 & 269 & 38 & & 1 & 5 & 61 & 13 \\
\hline & $\geq 2$ & 2 & 44 & 895 & & $\geq 2$ & 1 & 21 & 1200 \\
\hline
\end{tabular}

CHADS, congestive heart failure, hypertension, age $\geq 75$ years, diabetes mellitus, stroke; VASc, vascular disease, aged $65-74$ years, sex category.

\section{Comparison between $\mathrm{CHADS}_{2}$ and $\mathrm{CHA}_{2} \mathrm{DS}_{2}-\mathrm{VASc}$ risk scores}

The distribution of both $\mathrm{CHADS}_{2}$ and $\mathrm{CHA}_{2} \mathrm{DS}_{2}$-VASc scores is demonstrated in Table 4. Of the 64 patients classified as low risk with $\mathrm{CHADS}_{2}$ schema (score $=0$ ), only 16 patients were classified at low risk with $\mathrm{CHA}_{2} \mathrm{DS}_{2}$-VASc schema (score $=0$ ), while 30 patients could be estimated at intermediate risk based on $\mathrm{CHA}_{2} \mathrm{DS}_{2}-\mathrm{VASc}$ score $=1$ ( 9 women $<65$ years, 20 men between 65 and 74 years and 1 man with vascular disease). Finally, 18 patients were reclassified into high embolic risk with a $\mathrm{CHA}_{2} \mathrm{DS}_{2^{-}}$ $\mathrm{VASc}=2$ (15 women between 65 and 74 years and 3 men with vascular disease).

Table 4. The number of patients with each $\mathrm{CHADS}_{2}$ score and the number of patients changed to each new score when evaluated by $\mathrm{CHA}_{2} \mathrm{DS}_{2}$-VASc score

\begin{tabular}{rl}
\hline \multicolumn{1}{l}{ Risk scores } & Number of patients \\
\hline $\mathrm{CHADS}_{2}=0$ & 64 \\
$\mathrm{CHA}_{2} \mathrm{DS}_{2}-\mathrm{VASc}=0$ & 16 \\
$\mathrm{CHA}_{2} \mathrm{DS}_{2}-\mathrm{VASc}=1$ & 30 \\
$\mathrm{CHA}_{2} \mathrm{DS}_{2}-\mathrm{VASc}=2$ & 18 \\
$\mathrm{CHADS}_{2}=1$ & 318 \\
$\mathrm{CHA}_{2} \mathrm{DS}_{2}-\mathrm{VASc}=0$ & 0 \\
$\mathrm{CHA}_{2} \mathrm{DS}_{2}-\mathrm{VASc}=1$ & 56 \\
$\mathrm{CHA}_{2} \mathrm{DS}_{2}-\mathrm{VASc}=2$ & 137 \\
$\mathrm{CHA}_{2} \mathrm{DS}_{2}-\mathrm{VASc}=3$ & 123 \\
$\mathrm{CHA}_{2} \mathrm{DS}_{2}-\mathrm{VASc}=4$ & 2 \\
& \\
\hline
\end{tabular}

CHADS, congestive heart failure, hypertension, age $\geq 75$ years, diabetes mellitus, stroke; VASc, vascular disease, aged 65-74 years, sex category. 
Regarding 318 patients classified as intermediate risk with $\mathrm{CHADS}_{2}$ schema (score $=1$ ), only 56 patients were classified as intermediate risk with the new risk scale, $\mathrm{CHA}_{2} \mathrm{DS}_{2}-\mathrm{VASc}=1$, whereas 137 patients were reclassified as high risk, $\mathrm{CHA}_{2} \mathrm{DS}_{2}$-VASc score $=2$ (12 women $<65$ years, 88 men between 65 and 74 years, 27 men $>75$ years and 10 men $<65$ years with vascular disease). A total of 123 patients were reclassified into higher grade of thromboembolic risk $\mathrm{CHA}_{2} \mathrm{DS}_{2}-\mathrm{VASc}=3$ (73 women between 65 and 74 years, 32 women $>75$ years, 13 men between 65 and 74 years with vascular disease and 5 men $>75$ years with vascular disease). Finally, two patients with $\mathrm{CHADS}_{2}$ score $=1$ were reclassified into $\mathrm{CHA}_{2} \mathrm{DS}_{2}-\mathrm{VASc}=4$ (two women between 65 and 74 years with vascular disease).

Of our cohort, $81.1 \%$ of patients with $\mathrm{CHADS}_{2}$ score $=0-1$, and $23.0 \%$ of all patients were reclassified into higher grade of thromboembolic risk with $\mathrm{CHA}_{2} \mathrm{DS}_{2}-\mathrm{VASc}$ score.

After reclassification, patients with $\mathrm{CHA}_{2} \mathrm{DS}_{2}-\mathrm{VASc} \geq 2$ required antithrombotic therapy and patients with $\mathrm{CHA}_{2} \mathrm{DS}_{2}$-VASc $=1$ were considered to start anticoagulation treatment. Nevertheless, latest European guidelines ${ }^{6}$ recommend female patients with $\mathrm{CHA}_{2} \mathrm{DS}_{2}-\mathrm{VASc}=1$ due to gender alone as a single risk factor (nine women in our study) would not need anticoagulation if they clearly fulfil only the criteria of 'age < 65 years'. These women younger than 65 years have a low risk for stroke $(0.7 \%$ per year) and do not need anticoagulation treatment. ${ }^{17}$

\section{Discussion}

The findings of this study confirm that Spanish physicians correctly calculate thromboembolic risk scores. Manual $\mathrm{CHADS}_{2}$ and $\mathrm{CHA}_{2} \mathrm{DS}_{2}$-VASc risk scores showed excellent concordance with both computer-based risk scores.

The major advantage to use $\mathrm{CHADS}_{2}$ score has always been its simplicity, because this score is a straightforward algorithm consisting of a small number of variables. Most clinicians who manage patients with AF become familiar with $\mathrm{CHADS}_{2}$ score as a guide to stroke risk due to its simplicity. Nevertheless, this score does not discriminate particularly well between very low-risk patients and intermediate risk patients with AF. Therefore, $\mathrm{CHA}_{2} \mathrm{DS}_{2}$-VASc has been included in guidelines to be more inclusive of common stroke risk factors with three new variables. However, $\mathrm{CHA}_{2} \mathrm{DS}_{2}-\mathrm{VASc}$ score calculation is more complex and may involve errors. ${ }^{18}$

In this study, we analysed the comparison between manual and computer-based calculation of both $\mathrm{CHADS}_{2}$ and $\mathrm{CHA}_{2} \mathrm{DS}_{2}$-VASc scores. We have seen that there is a high correlation between scores obtained by computer-based and manual calculation.

For $\mathrm{CHADS}_{2}$ score, there is a $92 \%$ of concordance, while for $\mathrm{CHA}_{2} \mathrm{DS}_{2}-\mathrm{VASc}$ score there is a $96.4 \%$ of concordance between both systems. Despite $\mathrm{CHADS}_{2}$ score is simpler to calculate, in our study it has been observed greater concordance in the calculation of $\mathrm{CHA}_{2} \mathrm{DS}_{2}-\mathrm{VASc}$ score. Maybe these results showed the knowledge and adherence of Spanish physicians to the last guidelines and clinical practices for the treatment of AF.

These results lead to a change in antithrombotic therapy in $3.49 \%$ of patients whose stroke risk was calculated with $\mathrm{CHADS}_{2}$ score and only $0.45 \%$ of patients with $\mathrm{CHA}_{2} \mathrm{DS}_{2}-\mathrm{VASc}$ score. These findings show minimal changes in anticoagulation recommendations according to the manual or computer-based scoring system used with $\mathrm{CHA}_{2} \mathrm{DS}_{2}$-VASc score, but for $\mathrm{CHADS}_{2}$ score this change in anticoagulation recommendation is higher, being close to $5 \%$.

In addition, we reported that $\mathrm{CHA}_{2} \mathrm{DS}_{2}$-VASc score can further refine stroke risk stratification better than $\mathrm{CHADS}_{2}$ score, and this scoring system may be an useful tool to predict with more precision thromboembolic events in patients with AF. In our study, using $\mathrm{CHADS}_{2}$ score we identified $24.1 \%$ of patients with intermediate risk $\left(\mathrm{CHADS}_{2}\right.$ score $\left.=1\right)$ and $71.0 \%$ of patients with $\mathrm{AF}$ were identified with high-thromboembolic risk $\left(\mathrm{CHADS}_{2} \geq 2\right)$. When $\mathrm{CHA}_{2} \mathrm{DS}_{2}$-VASc score was used to stratify stroke risk, the intermediate risk $\left(\mathrm{CHA}_{2} \mathrm{DS}_{2}-\mathrm{VASc}=1\right)$ decreased to 6.5 and $92.3 \%$ of all patients of $\mathrm{AF}$ were 
classified as high risk with $\mathrm{CHA}_{2} \mathrm{DS}_{2}-\mathrm{VASc}$ score (score $\geq 2$ ). This study has shown that when we reclassified patients with $\mathrm{CHADS}_{2}$ score into $\mathrm{CHA}_{2} \mathrm{DS}_{2}$-VASc score, more than $20 \%$ of all patients were reclassified to a high-risk stratum by $\mathrm{CHA}_{2} \mathrm{DS}_{2}-\mathrm{VASc}$ score. In the controversial low/intermediate group of $\mathrm{CHADS}_{2}$ 0-1 score, $81.1 \%$ of patients in this group were reclassified into higher grade of thromboembolic risk with $\mathrm{CHA}_{2} \mathrm{DS}_{2}$-VASc score. Importantly, we estimated $4.9 \%$ patients at low risk by $\mathrm{CHADS}_{2}$ score $\left(\mathrm{CHADS}_{2}=0\right)$, whereas only $1.2 \%$ of all patients with AF were classified into low risk with $\mathrm{CHA}_{2} \mathrm{DS}_{2}-\mathrm{VASc}$. These findings are consistent with the increasing literature from multiple different cohorts that $\mathrm{CHA}_{2} \mathrm{DS}_{2}$-VASc score is better than $\mathrm{CHADS}_{2}$ specially in identification of truly low-risk patients $\left(\mathrm{CHA}_{2} \mathrm{DS}_{2}-\mathrm{VASc}=0\right)$ who may not need any thrombotic therapy and $\mathrm{CHA}_{2} \mathrm{DS}_{2}-\mathrm{VASc}$ is better in reducing patients classified in intermediate risk score. ${ }^{1,15}$ Our results are consistent with American 8 and European ${ }^{6}$ clinical guidelines for the management of patients with AF. Both guidelines now recommend the use of $\mathrm{CHA}_{2} \mathrm{DS}_{2}$-VASc score for risk stratification because $\mathrm{CHA}_{2} \mathrm{DS}_{2}$-VASc score identified those patients who are truly at low risk. As a consequence, fewer patients were assigned to the low-risk category with $\mathrm{CHA}_{2} \mathrm{DS}_{2}$-VASc score than when using $\mathrm{CHADS}_{2}$ score. Our clinical data showed that $382(28.9 \%)$ patients were classified as $\mathrm{CHADS}_{2} 0-1$, whereas only $102(7.7 \%)$ were classified as $\mathrm{CHA}_{2} \mathrm{DS}_{2}$-VASc 0-1 score. Moreover, the nationwide Danish registry showed, similar to FANTASIIA registry, that event in patients categorised as 'low risk' using a $\mathrm{CHADS}_{2}$ score $=0$, the $\mathrm{CHA}_{2} \mathrm{DS}_{2}$-VASc score significantly improved the predictive value of the $\mathrm{CHADS}_{2}$ score alone. ${ }^{7}$

Indeed, there is a change of perspective. The goal of the $\mathrm{CHA}_{2} \mathrm{DS}_{2}-\mathrm{VASc}$ score is to identify the truly low-risk patients who do not require oral anticoagulation therapy. ${ }^{13}$ Multiple studies have demonstrated that physicians do not adhere well to the current anticoagulation guidelines. ${ }^{19}$ In the study of validation of $\mathrm{CHA}_{2} \mathrm{DS}_{2}$-VASc, a Danish cohort, including $47576 \mathrm{AF}$ patients with $\mathrm{CHADS}_{2}$ score 0-1 without warfarin treatment, thromboembolic events occurred at 3.49\%/year compared with $0.84 \% / y e a r$ and $1.79 \% / y e a r$ in the patient groups reclassified as having $\mathrm{CHA}_{2} \mathrm{DS}_{2}-\mathrm{VASc}$ scores of 0 and 1 respectively. ${ }^{10}$ These results confirm that patients with $\mathrm{CHADS}_{2}$ score of 0 were not all at low risk and anticoagulation decision based simply on $\mathrm{CHADS}_{2}$ score may underestimated the real risk in patients with $\mathrm{AF}$, and the use of $\mathrm{CHA}_{2} \mathrm{DS}_{2}$-VASc score significantly improves reclassification of AF patients. The clinical consequence of this reclassification is substantial to start anticoagulation treatment. In our study, according to the latest European guidelines on $\mathrm{AF}^{6}{ }^{6}$ using $\mathrm{CHADS}_{2}$ score $71.0 \%$ of patients with $\mathrm{AF}$ would have the recommendation to start oral anticoagulation, whereas using $\mathrm{CHA}_{2} \mathrm{DS}_{2}-\mathrm{VASc}$ score, $92.3 \%$ of patients with $\mathrm{AF}\left(\mathrm{CHA}_{2} \mathrm{DS}_{2}-\mathrm{VASc} \geq 2\right)$ would have definite indication of start oral anticoagulation and $6.5 \%$ of patients with $\mathrm{AF}\left(\mathrm{CHA}_{2} \mathrm{DS}_{2}\right.$-VASc $\left.=1\right)$ would have consider indication of start oral anticoagulation therapy. ${ }^{6}$

As mentioned above, $\mathrm{CHADS}_{2}$ score does not classify patients with low or intermediate thromboembolic risk correctly so any small change between scores obtained by computer-based and manual calculation could involve a substantial change in indication of anticoagulation and, if calculated wrongly, may increase the thromboembolic risk in patients with AF.

As a result of these findings, physicians correctly calculate risk scores, specifically $\mathrm{CHA}_{2} \mathrm{DS}_{2}-\mathrm{VASc}$ score which is more complex because it includes more items, so the lack of adherence of clinical guidelines is due to other problems that need to be analysed in detail.

\section{Study limitations}

This article only reports the baseline data of the FANTASIIA registry and follow up is ongoing. A more comprehensive assessment of the data on the management and treatment of AF in population would be obtained from FANTASIIA long-term registry which is scheduled in 2016. Most of our patients were under acenocoumarol. Acenocoumarol is the most common VKA used in Spain and shows a shorter halflife than warfarin (10 vs $36 \mathrm{~h}$ ), but without differences on the time on therapeutic range. 


\section{Conclusions}

We have found a strong concordance between manual and computer-based score calculation of both $\mathrm{CHADS}_{2}$ and $\mathrm{CHA}_{2} \mathrm{DS}_{2}-\mathrm{VASc}$ risk scores. These findings show minimal changes in anticoagulation recommendations according to the manual or computer-based scoring system used above with $\mathrm{CHA}_{2} \mathrm{DS}_{2}{ }^{-}$ VASc risk score. In addition, the use of $\mathrm{CHA}_{2} \mathrm{DS}_{2}$-VASc score significantly improves the classification of AF patients at low and intermediate risk of stroke into higher grade of thromboembolic score, which would have indication of oral anticoagulation therapy, and could identify 'truly low risk' patients compared with the commonly used $\mathrm{CHADS}_{2}$ score, being consistent with the finding in several cohorts.

\section{Acknowledgements}

This project has been developed under the agreement of Agencia de Investigación de la Sociedad Española de Cardiología. We thank all investigators who have collaborated in the FANTASIIA registry.

\section{References}

1. Lip GYH, Nieuwlaat R, Pisters R, Lane DA , Crijns HJGM . Refining clinical risk stratification for predicting stroke and thromboembolism in atrial fibrillation using a novel risk factor-based approach: the Euro heart survey on atrial fibrillation. Chest 2010; 137: 263-72.

2. The Task Force for the Management of Atrial Fibrillation of the European Society of Cardiology (ESC). Guidelines for the management of atrial fibrillation. Eur Heart J 2010; 31: 2369-429.

3. Lip GYH . Stroke and bleeding risk assessment in atrial fibrillation: when, how, and why? Eur Heart $J$ 2013; 34: 1041-9.

4. Roldán V , Marín F, Manzano-Fernández S, Gallego P, Vílchez JA, Valdés M et al. The HAS-BLED score has better prediction accuracy for major bleeding than CHADS2 or CHA2DS2-VASc scores in anticoagulated patients with atrial fibrillation. J Am Coll Cardiol 2013; 62: 2199-204.

5. Mason PK, Lake DE, DiMarco JP, Ferguson JD, Mangrum JM, Bilchick K et al. Impact of the $\mathrm{CHA}_{2} \mathrm{DS}_{2}$-VASc score on anticoagulation recommendations for atrial fibrillation. Am J Med 2012; 125 : 603.e1-6.

6. Camm AJ, Lip GYH, De Caterina R, Savelieva I, Atar D, Hohnloser SH et al. 2012 focused update of the ESC Guidelines for the management of atrial fibrillation. Eur Heart J 2012; 33: 2719-47.

7. Olesen JB , Torp-Pedersen C, Hansen ML, Lip GYH . The value of the CHA2DS2-VASc score for refining stroke risk stratification in patients with atrial fibrillation with a CHADS2 score 0-1: a nationwide cohort study. Thromb Haemost 2012; 107: 1172-9.

8. Anderson JL, Halperin JL, Albert NM , Bozkurt B , Brindis RG, Curtis LH et al. Management of patients with atrial fibrillation (Compilation of 2006 ACCF/AHA/ESC and 2011 ACCF/AHA/HRS recommendations): a report of the American College of Cardiology/American Heart Association Task Force on Practice Guidelines

9. Coppens M, Eikelboom JW, Hart RG, Yusuf S, Lip GYH, Dorian P et al. The CHA2DS2-VASc score identifies those patients with atrial fibrillation and a CHADS2 score of 1 who are unlikely to benefit from oral anticoagulant therapy. Eur Heart J 2013; 34: 170-6.

10. Jover E, Roldán V, Gallego P, Hernández-Romero D, Valdés M, Vicente V et al. Predictive value of the CHA2DS2-VASc score in atrial fibrillation patients at high risk for stroke despite oral anticoagulation. Rev Esp Cardiol (Engl Ed) 2012; 65: 627-33.

11. Nattel S, Guasch E, Savelieva I, Cosio FG, Valverde I, Halperin JL et al. Early management of atrial fibrillation to prevent cardiovascular complications. Eur Heart J 2014; 35: 1448-56.

12. Lip GYH, Laroche C, Dan G-A, Santini M, Kalarus Z, Rasmussen LH et al. A prospective survey in European Society of Cardiology member countries of atrial fibrillation management: baseline results of EURObservational Research Programme Atrial Fibrillation (EORP-AF) pilot general registry. Europace 2014; 16: 308-19.

13. Anderson JL, Halperin JL, Albert NM , Bozkurt B , Brindis RG, Curtis LH et al. Management of patients with atrial fibrillation (compilation of 2006 ACCF/AHA/ESC and 2011 ACCF/AHA/HRS recommendations): a report of the American College of Cardiology/American Heart Association Task Force on Practice Guidelines. J Am Coll Cardiol 2013; 61: 1935-44. 
14. Lane DA , Lip GYH . Use of the CHA(2)DS(2)-VASc and HAS-BLED scores to aid decision making for thromboprophylaxis in nonvalvular atrial fibrillation. Circulation 2012; 126: 860-5.

15. Lip GYH, Frison L, Halperin JL, Lane DA . Identifying patients at high risk for stroke despite anticoagulation: a comparison of contemporary stroke risk stratification schemes in an anticoagulated atrial fibrillation cohort. Stroke 2010; 41: 2731-8.

16. Okumura $\mathrm{K}$, Inoue $\mathrm{H}$, Atarashi $\mathrm{H}$, Yamashita $\mathrm{T}$, Tomita $\mathrm{H}$, Origasa $\mathrm{H}$ et al. Validation of $\mathrm{CHA}_{2} \mathrm{DS}_{2^{-}}$ VASc and HAS-BLED scores in Japanese patients with nonvalvular atrial fibrillation: an analysis of the J-RHYTHM Registry. Circ J 2014; 78: 1593-9.

17. Friberg L, Benson L, Rosenqvist M, Lip GYH . Assessment of female sex as a risk factor in atrial fibrillation in Sweden: nationwide retrospective cohort study. BMJ 2012; 344: e3522.

18. Fuster V , Rydén LE, Cannom DS , Crijns HJ , Curtis AB , Ellenbogen KA et al. ACC/AHA/ESC 2006 guidelines for the management of patients with atrial fibrillation - executive summary: a report of the American College of Cardiology/American Heart Association Task Force on Practice Guidelines and the European Society of Cardiology Committee for Practice Guidelines (Writing Committee to Revise the 2001 Guidelines for the Management of Patients with Atrial Fibrillation). Eur Heart J 2006; 27 : 1979-2030.

19. Winkle RA, Mead RH , Engel G, Kong MH , Patrawala RA . Comparison of CHADS2 and CHA2DS2-VASC anticoagulation recommendations: evaluation in a cohort of atrial fibrillation ablation patients. Europace 2014; 16: 195-201. 